Research Article

\title{
New Method for Calculating the Settlement of Single Pile and Pile Group in Soft Soil Area
}

\author{
Jingjing Xu $\mathbb{D}, \mathrm{Xu} X \mathbf{X}$, and Wenjuan Yao $\mathbb{C}$ \\ School of Mechanics and Engineering Science, Shanghai University, Shanghai 200444, China \\ Correspondence should be addressed to Wenjuan Yao; wjyao@shu.edu.cn
}

Received 25 May 2020; Revised 1 October 2020; Accepted 20 October 2020; Published 11 November 2020

Academic Editor: Jia-wen Zhou

Copyright (C) 2020 Jingjing Xu et al. This is an open access article distributed under the Creative Commons Attribution License, which permits unrestricted use, distribution, and reproduction in any medium, provided the original work is properly cited.

\begin{abstract}
This paper fits the $\tau$ - $\mathrm{z}$ curve of a single pile by mathematical methods. Based on the one-dimensional similarity of the $\tau$ - $\mathrm{z}$ curves, the $\tau$-z curves of single pile under different loads are derived. It studies the distribution of the axial force of a single pile by taking the self-weight of the pile and the pile-end resistance ratio into account and establishes the calculated equation of settlement for single pile. The mutual reinforcing effect between the piles is fully considered, and the settlement of each foundation pile in the pile group is deduced in use of shear displacement method. The example analysis shows that the axial force distribution of single pile considering the self-weight and the pile-end resistance ratio is in good agreement with the experimental data. The settlement error of a single pile calculated by the traditional method is $18.52 \%$ compared with measured value. When the self-weight and end resistance ratio are not considered, the error reaches $2.26 \%$. However, the error could reduce to $1.64 \%$ when they are taken into consideration. It has a good applicability to calculate the settlement of pile group through the $\tau$-z curves of single pile. Also, it can better forecast the settlement behavior of the pile group under similar conditions.
\end{abstract}

\section{Introduction}

In the past decades, some methods have been used for the settlement calculation of pile groups. They mainly include equivalent pier foundation method, layered summation method, load transfer method, and finite element analysis method [1]. A great deal of research has been done on the application of these methods. The equivalent pier foundation method and the layered summation method take the pile group and the cap to be a whole, which is good for calculating the overall settlement of the pile group. However, it cannot analyze the differential settlement between the piles in the pile group foundation. The load transfer method is very effective in calculating the settlement of a single pile, while it cannot account for the continuity of the soil and the interaction between the pile and surrounding soil as used in group pile calculation. The finite element analysis method can well describe the geometric characteristics of the pile group and the specific parameters of the soil around the pile. However, due to the complexity of modeling, the calculation accuracy is greatly affected by the selection of the parameters, which results in some limitations in engineering applications to some extent.

The shear displacement method was proposed by Cooke in 1974. The soil displacement caused by the shaft shear stress is regarded as the logarithmic relation of radial distance away from pile. The interaction among piles can be considered by the superposition principle. It is a simple and efficient method in analyzing the response of axially loaded pile $[2,3]$. Later, the shear displacement method is used to analyze pile group effect and pile-pile interaction $[4,5]$. Based on shear displacement method, Lin et al. $[6,7]$ proposed a simplified formula of interaction coefficient and established a flexibility matrix equation for pile group settlement calculation.

In practical applications, static load tests of a single pile were carried out in the foundation design of most projects. This has attracted more and more attention from researchers about how to use single pile test results to effectively estimate the deformation behavior of pile groups.

Mostly, researchers estimated the settlement of pile groups through the load-settlement curve of a single pile. 
The foundation parameters are obtained through back analysis of the load test, and the interaction between the piles is described by the mutual interaction factor $[8,9]$. Mao and Jiang [10] analyzed the load test of a single pile and obtained the equivalent deformation modulus. The Mindlin solution, Boussinesq solution, and the superposition principle were used to compute the interaction between the piles in the pile group, and the $\mathrm{C}++$ program was compiled to calculate the settlement of pile group. Pan et al. [11] established a load transfer model for a single pile which is similar to hyperbolic function. Based on the Runge-Kutta method, they considered the pile to pile interaction and proposed an improved load transfer method to calculate response of the pile group. The key for calculating the settlement of pile group by a single pile is the analysis of the interactions among piles. Moreover, the consideration of the mutual reinforcing effects plays a very important role in analyzing the interactions between piles. Liang et al. [12], Yan and Zhang [13], and Xin [14] considered the effect of the foundation pile itself on the deformation of soil and studied the reinforcement effect of the pile group. Sheil and McCabe [15] took the reinforcement effect of unloaded pile into account and calculated the settlement of pile raft foundation by nonlinear iterative method. Not only is the settlement of the piles in the group pile foundation related to the skin friction of the piles, but also is closely related to the mutual reinforcement effect of other surrounding piles $[15,16]$.

In addition to the load-settlement curve, the $\tau$-z curves obtained from the static load test also contain rich information of pile-soil interaction. Moreover, it can well reflect the feedback of the pile and soil under the axial load. In this work, the $\tau$-z curves obtained from test under a certain load are fitted, and thus the $\tau$ - $z$ curves under different loads are derived from it. Considering the effect of the existence of piles on surrounding soil and the mutual reinforcing effect between piles, the settlement of pile group is deduced by the $\tau$-z curves of a single pile. By comparison with the numerical analysis method, the method proposed in this work greatly saves the calculation time, and the calculated results are in good agreement with test value.

\section{Fitting and Derivation of Single Pile}

Under the different axial load of pile top, although the magnitude of pile side friction along depth is different, its curves are close to each other along the tangent direction of the corresponding side friction when the depth changes. In other words, the development of pile side friction along the depth under different load levels has a certain proportion relationship. They are similar in one-dimensional direction. One-dimensional similarity was introduced to describe this phenomenon. In this work, based on an example, the functional expressions between the skin friction and the depth of a single pile are obtained by fitting. According to the one-dimensional similarity of $\tau-z$ curves, the disparate functional expressions under different loads are derived.

For the super-long pile in soft soil area, the bearing capacity provided by pile end is very small under working load. Almost all the bearing capacity is provided by the pile skin friction, and the settlement of the pile top almost comes from the compression of the pile body, which is shown as purely frictional pile $[15,17]$. Therefore, it is assumed that the piles studied in this paper behave as frictional piles.

A loading test on a single pile S3 in multilayered soils was obtained from Xin [18]. The site has 23.36 meters silty clay, and the thickness of the soft soil is $52.3 \mathrm{~m}$. The parameters of soils are as shown in Table 1. Figure 1 illustrates the schematic diagram of the pile and soil strata. The test pile, S3, is $1.1 \mathrm{~m}$ in diameter with a length of $88.17 \mathrm{~m}$. It is a typical super-long pile in the soft soil area. The bearing stratum is moderately weathered bedrock and the pile top settlement is $49.52 \mathrm{~mm}$ under bearing load.

In the literature, the $\tau$-z curves under different loads are similar. The parameter $\varphi=z / L_{a}$ is introduced where $L_{a}$ is the effective length of pile and $z$ is the depth from the pile top. In this paper, $L_{a}$ is taken as the value of pile length. $\tau(\varphi)$ is the value of skin friction with change of $\varphi$. The polynomial function is used to fit the relationship between skin friction and effective depth under a certain load $P_{0}$. When the polynomial is of order six in origin software, it is enough to meet the fitting accuracy requirements. Taking $P_{0}=9600 \mathrm{kN}$ as an example, the fitting function is obtained as follows:

$$
\begin{aligned}
\tau(\varphi)= & \sum_{i=0}^{i_{n}} g_{i} \varphi^{i}=0.43052-8.07 \times 10^{3} \varphi^{6}+2.49 \times 10^{4} \varphi^{5} \\
& -2.86 \times 10^{4} \varphi^{4}+1.50 \times 10^{4} \varphi^{3}-3.49 \times 10^{3} \varphi^{2} \\
& +3.52 \times 10^{2} \varphi
\end{aligned}
$$

In (1), $g_{i}$ is the polynomial coefficient [19]. The fitting curve and measured curve are shown in Figure 2. As shown in Figure 2, the skin friction first increases and then decreases with the increase of depth. The friction resistance along pile is gradually developed, and the skin friction of upper soil layer is prior to that of lower soil layer. It is an asynchronous process. The correlation coefficient of two curves, $R^{2}$, equals 0.9319 . The closer the value of $R^{2}$ is to 1 , the better the accuracy of fitting curve is.

It is not difficult to find from Xin et al. [18] that $\tau$-Z curves under different loads have some common features along the depth. The magnitude and direction of tangent slope of $\tau-z$ curves are approximately the same, though the values of skin friction are different at the same depth. There are similar situations found in other literatures, such as Zhu et al. [20], McCabe [21], and Chen [15]. It can also be said that there is one-dimensional similarity between $\tau$-z curves under different loads. Let $\tau_{0}(\varphi)$ be the fitting curve of skin friction; $\tau_{*}(\varphi)$ is the derived curve of skin friction at the same depth and $\Delta(\varphi)$ is any small differentiable function. The following is the derivation of the above-mentioned terms:

$$
\tau_{*}(\varphi)=\tau_{0}(\varphi)+\Delta(\varphi)
$$

Let

$$
\Delta(\varphi)=h \cdot \tau_{0}(\varphi),
$$


TABLe 1: Physical and mechanical parameters of soils.

\begin{tabular}{|c|c|c|c|c|}
\hline No. & Name & Bottom buried depth (m) & Density $\left(\mathrm{kN} / \mathrm{m}^{3}\right)$ & Water content (\%) \\
\hline 1 & Filling & $1.33 \sim 3.82$ & 17.38 & 43.5 \\
\hline $3-1$ & Silt & $10.50 \sim 11.40$ & 15.67 & 70.1 \\
\hline $3-2$ & Silt & $19.18 \sim 21.21$ & 16.10 & 64.7 \\
\hline $3-3$ & Muddy clay & $20.85 \sim 23.36$ & 17.27 & 50.5 \\
\hline $4-1$ & Clay & $22.48 \sim 24.36$ & 19.06 & 32.9 \\
\hline $4-2$ & Clay & $28.47 \sim 30.90$ & 18.20 & 40.9 \\
\hline $5-1$ & Silty clay with clay & $31.01 \sim 33.55$ & 19.33 & 29.9 \\
\hline $5-2$ & Clay & $34.26 \sim 38.85$ & 18.55 & 37 \\
\hline $6-1$ & Clay with silty clay & $38.96 \sim 45.60$ & 19.49 & 29.6 \\
\hline $6-2$ & Clay & $41.97 \sim 46.43$ & 18.40 & 36.8 \\
\hline $7-1$ & Clay with silty clay & 47.46 & 19.12 & 30.7 \\
\hline 8 & Silty clay mixed with reef & $42.92 \sim 52.30$ & -- & - - \\
\hline $9-1-1$ & Completely weathered bedrock & $58.68 \sim 69.52$ & - - & - - \\
\hline $9-1-2$ & Completely weathered bedrock & $75.46 \sim 105.76$ & - & - - \\
\hline $9-2$ & Strongly weathered bedrock & $84.48 \sim 114.48$ & - & - \\
\hline $9-3$ & Moderately weathered bedrock & Unpierced & - & - - \\
\hline
\end{tabular}

\begin{tabular}{c|l|l} 
M 1 X & KK K \\
\hline $3-1$ & & \\
\hline $3-2$ & & \\
\hline $3-3$ & & \\
\hline $4-1$ & & \\
\hline $4-2$ & & \\
\hline $5-1$ & & \\
\hline $5-2$ & & \\
\hline $6-1$ & & \\
\hline $6-2$ & & \\
\hline $7-1$ & & \\
\hline 8 & & \\
\hline $9-1$ & & \\
\hline $9-2$ & & \\
\hline $9-3$ & &
\end{tabular}

Figure 1: The schematic diagram of the pile and soil strata.

where $h$ is the infinitesimal parameter. Then, (2) changes to

$$
\tau_{*}(\varphi)=(1+h) \cdot \tau_{0}(\varphi) .
$$

And

$$
\begin{aligned}
& P_{0}=\pi D \int_{0}^{z} \tau_{0}(\varphi) \mathrm{d} z, \\
& P_{*}=\pi D \int_{0}^{z} \tau_{*}(\varphi) \mathrm{d} z=(1+h) \pi D \int_{0}^{z} \tau_{0}(\varphi) \mathrm{d} z,
\end{aligned}
$$

where $P_{0}, P_{*}$ is the corresponding load of $\tau_{0}(\varphi), \tau_{*}(\varphi)$, respectively. It is easy to get the value of $h$ by (6). Therefore, according to the one-dimensional similarity between the $\tau$-z curves under different loads in the same test, we can get the

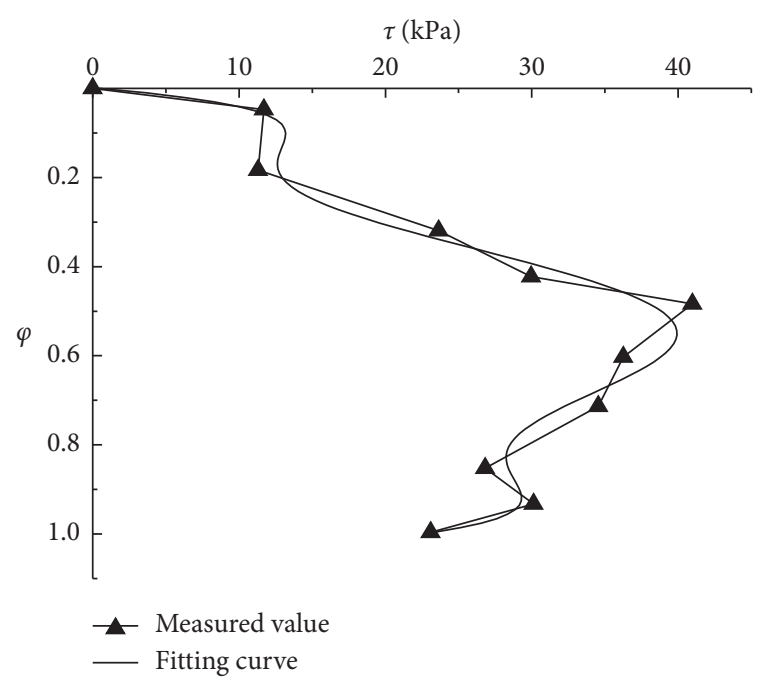

FIgURE 2: The fitting curve of skin friction when load is $9600 \mathrm{kN}$.

functional expressions between the skin friction and the effective depth under any load by

$$
\tau(z)=(1+h) \cdot \sum_{i=0}^{i_{n}} g_{i} \varphi^{i}=\frac{P_{*}}{P_{0}} \sum_{i=0}^{i_{n}} g_{i} \varphi^{i} .
$$

When the pile top load $P_{*}=12000 \mathrm{kN}$, substitute $P_{*}, P_{0}$, and (1) into (7). So, the functional expressions between pile skin friction and the depth can be written as

$$
\begin{aligned}
\tau(\varphi)= & 0.53815-1.009 \times 10^{4} \varphi^{6}+3.111 \times 10^{4} \varphi^{5} \\
& -3.579 \times 10^{4} \varphi^{4}+1.871 \times 10^{4} \varphi^{3}-4.357 \times 10^{3} \varphi^{2} \\
& +4.407 \times 10^{2} \varphi
\end{aligned}
$$

The calculated skin friction by derived equation is compared with the measured data, as shown in Figure 3. The correlation coefficient $R^{2}$ is 0.9336 , which verifies the correctness of the derived equation. 


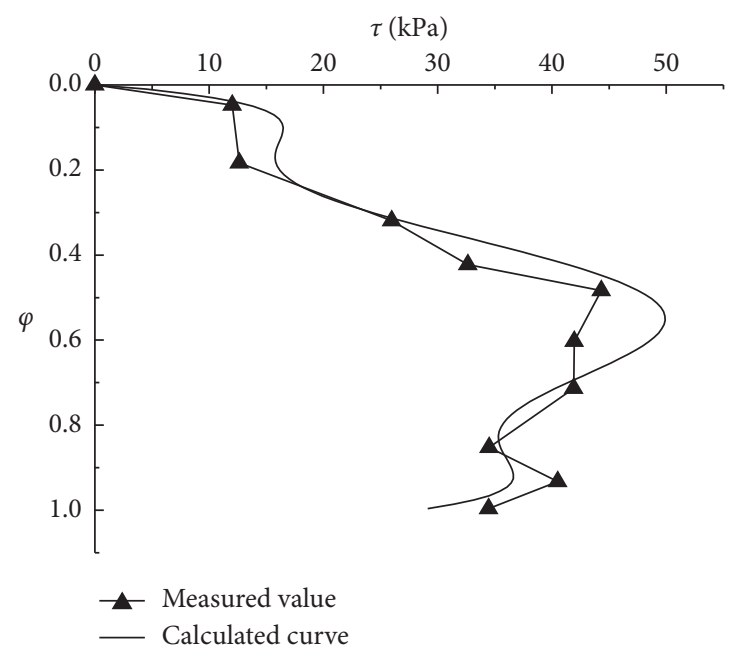

Figure 3: The comparison of measured and derived curves when load is $12000 \mathrm{kN}$.

TABLE 2: The correlation coefficient under different pile top loads.

\begin{tabular}{lccccccrr}
\hline$P(\mathrm{kN})$ & 4800 & 7200 & 14400 & 18000 & 20400 & 22800 & 24000 & 25200 \\
\hline$R^{2}$ & 0.8617 & 0.9688 & 0.9622 & 0.9496 & 0.9683 & 0.9742 & 0.9747 & 0.9722 \\
\hline
\end{tabular}

The correlation coefficients between the derived function and the measured data under different pile top loads are shown in Table 2. The closer the correlation coefficient is to 1 , the closer the two types of data are. It can be seen from Table 2 that, under different top loads, the minimum value of the fitting correlation coefficient is 0.8617 and the maximum value is 0.9745 which indicates that the calculated and derived value have a good fit.

The method proposed also has been applied to different field test [21]. Taking $P_{0}$ as $46 \mathrm{kN}$ in this case. When pile top load $P_{*}$ is taken as different values, the derived functions can be obtained in use of the same method. The correlation coefficients $R^{2}$ are shown in Table 3. A good agreement between the measured values and derived curves is generally observed from Table 3. Moreover, the reliability of the proposed method in this paper is further proved.

\section{Case Study on Response of Single Pile}

The case analyzed was presented by Chen [15]. A friction super-long pile was driven to a penetration of $67.5 \mathrm{~m}$ and had a diameter of $0.85 \mathrm{~m}$. The bearing capacity of single pile was designed as $12000 \mathrm{kN}$. The concrete strength grade of the pile is C50 and the elastic modulus was adopted as $34.5 \mathrm{GPa}$.

The $\tau$ - $z$ curves under different loads can be obtained from the literature of Chen [15]. Firstly, a polynomial is used to fit the functional expressions between the pile skin friction $\tau$ and parameter $\varphi$ when $P_{0}=9600 \mathrm{kN}$, as shown in the following equation:

$$
\tau_{0}(\varphi)=1019.3 \varphi^{4}-2207.2 \varphi^{3}+1462.1 \varphi^{2}-231.23 \varphi+26.248 .
$$

TABle 3: The correlation coefficient.

\begin{tabular}{lcccc}
\hline$P(\mathrm{kN})$ & 17 & 56 & 30 & 50 \\
\hline$R^{2}$ & 0.9619 & 0.9926 & 0.9265 & 0.9992 \\
\hline
\end{tabular}

In practical engineering, the pile end still provides small bearing capacity. When calculating the total skin friction of pile, the pile-end resistance ratio $\beta$ is introduced in this case to consider the pile-end force in soft area. ' $\beta$ ' is equal to the pile-end force divided by the sum of pile-end force and the total skin friction. Assume that $\beta=0.06$ here when combining the test data in soft soil area $[22,23]$. When the top load $P_{*}=8400 \mathrm{kN}$, the pile skin friction can be expressed by the following equation according to the one-dimensional similarity of skin friction curves under different loads:

$$
\begin{aligned}
\tau_{i 0}(\varphi)= & \frac{P_{*}(1-\beta)}{P_{0}} \tau_{0}(\varphi)=891.906 \varphi^{4}-1931.27 \varphi^{3} \\
& +1279.377 \varphi^{2}-202.329 \varphi+22.967 .
\end{aligned}
$$

The correlation coefficient $R^{2}$ is 0.9725 when $P_{0}$ is taken as $9600 \mathrm{kN}$. And the value of $R^{2}$ equals 0.9568 when $P_{*}$ is $8400 \mathrm{kN}$. Comparing the measured value with fitting curve and derived curve, the results are shown in Figure 4. As can be seen from Figure 4, the fitting curve and the derived curve in this paper can well reflect the variation rule of pile skin friction along the depth. In addition, they are in good agreement with the experimental value.

Because super-long pile has large length, neglecting the weight of the pile body during the calculation will have a greater impact on the calculation results. Therefore, it is 


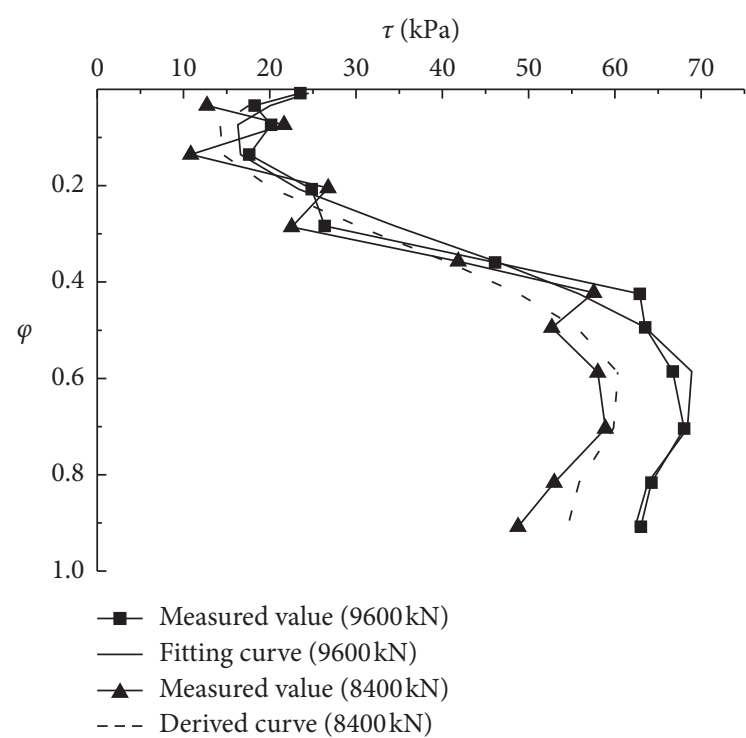

FIgURE 4: The comparison of different curves.

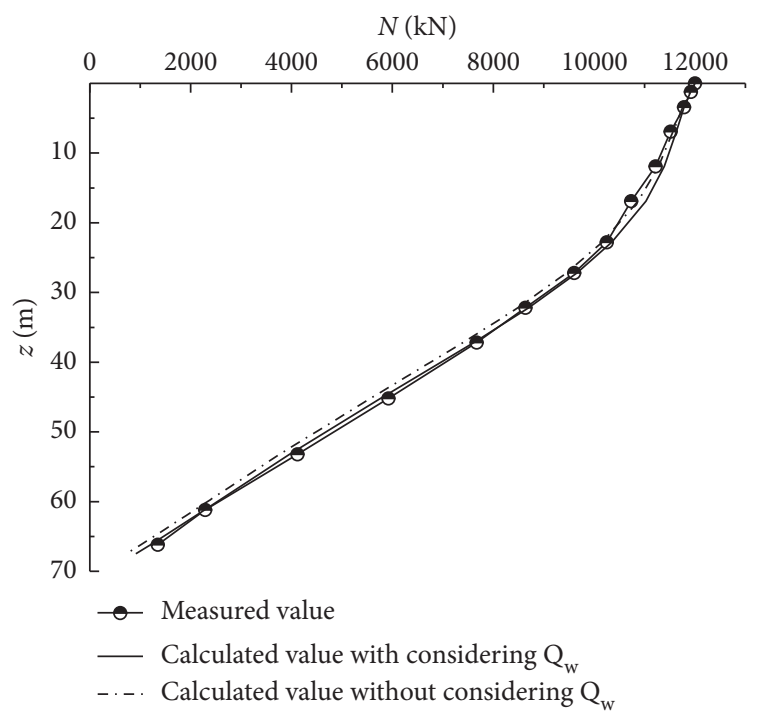

Figure 5: Comparison of axial force distribution of a single pile.

particularly necessary to consider the self-weight of superlong pile. The axial force of a super-long pile can be expressed by the first following equation, and the total skin friction along the pile can be calculated by the second following equation. Thus, we can easily obtain the axial force at different depths along the pile. When taking and not taking the self-weight of the pile into account, the distributions of the axial force along the depth direction are calculated and compared with the experimental data, as shown in Figure 5:

$$
\begin{aligned}
& N=P_{i}+Q_{w}-T, \\
& T=\pi D \int_{0}^{L_{a}} \tau_{i 0}(\varphi) \mathrm{d} z,
\end{aligned}
$$

where $N$ is the axial force of the pile; $P_{i}$ is the acting load at the top of the pile; $Q_{w}$ is the self-weight of the pile body; $T$ is the total frictional resistance in the range of 0 to $z$.

As can be seen from Figure 5, the axial force of pile decreases gradually with the increase of depth. The decrease of axial force in the upper part of pile body is very slow, and it increases gradually as the depth continues to increase. When the pile top load is $120,00 \mathrm{kN}$, the errors of axial force at the depths of $37.2 \mathrm{~m}$ and $66.2 \mathrm{~m}$ without considering the self-weight of pile are $3.4 \%$ and $24.56 \%$, respectively. After considering the weight of pile, the errors are reduced to $0.75 \%$ and $11 \%$, respectively. It is closer to the experimental data of axial force distribution when considering the selfweight of super-long pile. Therefore, it is quite necessary to consider the self-weight of the pile in the analysis of the settlement of the super-long pile and the force distribution along the pile.

Since load of pile top $P_{i}$ and weight of pile $Q_{w}$ are constant values, the key to calculate the axial force $\mathrm{N}$ is the calculation of total frictional resistance $T$ according to (11). The value of $T$ is obtained based on fitting polynomial. From Figure 4, it can be found that the simulation effect of the side friction $\tau$ is slightly worse than the lower part of the pile when $\varphi$ is on the range of 0 to 0.4 . This also leads to the error of total frictional resistance $T$ while $\varphi$ is between 0 and 0.4 . Hence, the error of the axial force $\mathrm{N}$ is slightly larger when considering $Q_{w}$ around the depth of $0-28 \mathrm{~m}$ in Figure 5. However, this does not affect the overall consistency of the calculated axial force with the experimental data when $Q_{w}$ is considered.

In practice, the super-long piles mostly appear as frictional piles. However, the pile end also bears part of the force. Figure 6 is the comparisons of the axial force distribution when considering and not considering the end resistance ratio of super-long pile as well as the measured value. It can also be seen from Figure 6 that the axial force of the pile is significantly smaller than experimental value without considering the end resistance ratio $\beta$. As the pile top load is $120,00 \mathrm{kN}$, the errors of axial force at the depths of $37.2 \mathrm{~m}$ and $66.2 \mathrm{~m}$ without considering the end resistance ratio are $-3.4 \%$ and $-38.08 \%$, respectively. The errors after considering the end resistance ratio are reduced to $0.21 \%$ and $8.5 \%$, respectively. Consequently, in this paper, distribution analysis of axial force with taking the end resistance ratio $\beta$ into account is more consistent with the actual condition. The calculated axial force is more in line with the experimental value as well.

The settlement of pile under axial load is mainly composed of the compression of pile body and the soil at end of pile. In practice, the load on the pile end is very small. The pile top load is mainly borne by the skin friction, which mostly appears as friction piles. Zhang [24, 25] carried out a lot of researches on super-long piles. According to the experimental results, the compression of the pile body accounts for a large part of the total settlement, and the proportion can reach more than $80 \%$ under the ultimate load. In area of deep soft soil, this phenomenon is more 


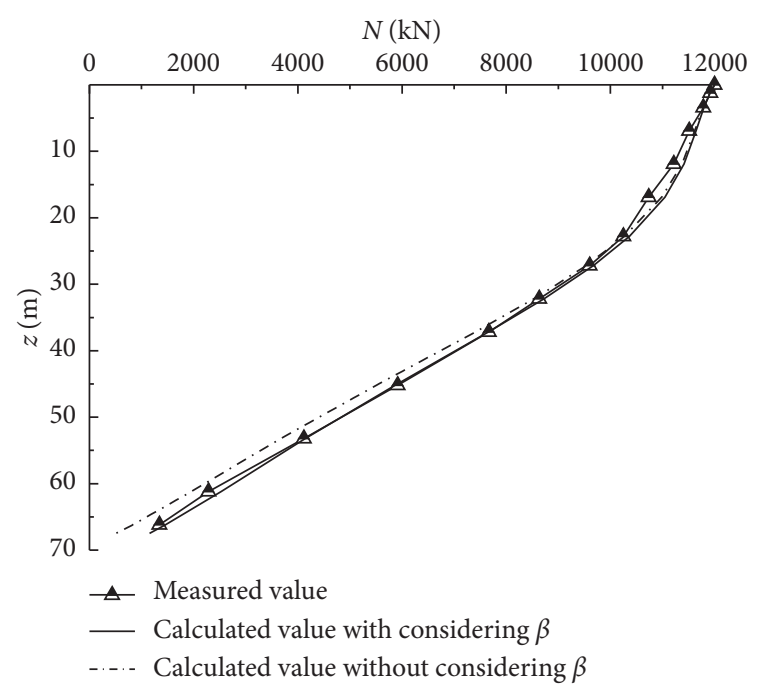

Figure 6: Comparison of axial force distribution of a single pile.

TABLE 4: The comparison of settlement in different methods.

\begin{tabular}{lcccc}
\hline & Measured value & The method of code & $\beta=0$ & $\beta=0.06$ \\
\hline Value & 22.57 & 18.39 & 22.06 & 22.94 \\
Error (\%) & 0 & -18.52 & -2.26 & 1.64 \\
\hline
\end{tabular}

common. The settlement of a single pile mainly originates from the elastic compression of the pile so that the settlement of the soil at the end of the pile is ignored in analysis. Based on classic Hooke's law of member compression, we can calculate the settlement of a single pile under axial load by the following equation:

$$
w_{i}=\frac{1}{E A_{p}} \int_{0}^{L_{a}}\left[P_{i}+Q_{w}-T\right] \mathrm{d} Z
$$

where $E$ is the elastic modulus of the pile body. $A_{p}$ is the cross-sectional area of pile.

Table 4 compares the settlement values of simplified calculation method in the code, method in this work and the experiment. It can be seen that the error between the simplified calculation method in the code and the measured value is $18.52 \%$. When the end resistance ratio $\beta$ is not considered, the error between calculation method in this paper and experimental value is $2.26 \%$. However, the error is reduced to $1.64 \%$ when end resistance ratio $\beta$ is considered, which shows a good agreement with the experimental value. The traditional method assumes that the distribution of axial force along the pile is just like an inverted triangle. This assumption means that pile end is not subjected to force, which will produce a large error in the calculation. The method presented in this paper considers the force borne by the pile end, and the calculated value is slightly larger than the measured value, which indicates that it is safe in actual engineering.

\section{Settlement Behavior of Pile Group}

4.1. Derivation of Pile Group. By using $\tau$-z curve of a single pile, the functional expressions between the pile skin friction and the depth of a foundation pile in a pile group can be obtained. Fully considering the mutual reinforcing effect of piles in pile groups, thus the deformation behavior of the foundation pile is derived.

The reinforcing effect in pile group is mainly caused by the shear stress of the pile side. In this paper, the shear stress on the side of a single pile is connected to that on the side of a foundation pile in a pile group. The specific analysis is as follows:

When pile $i$ exists independently and the axial load $P_{i}$ is applied on the top of the pile $i, \tau_{i 0}$ is taken as the skin friction at the depth $z$ of pile $i$. At the same time, in the above case, when the adjacent pile $j$ exists and the pile top is unloaded, the skin friction $\tau_{i 0}$ in the soil around the pile $i$ is transmitted radially outward based on the thin ring concentric cylinder shear mode. Then, $\tau_{j i}$, the skin friction of the pile $j$ at the same depth, can be written as the following equation according to Randolph and Worth [26]:

$$
\tau_{j i}=\frac{\tau_{i 0} r_{0}}{S_{i j}} \quad\left(r_{0} \leq S_{i j} \leq r_{m}\right)
$$

where $S_{i j}$ is the center to center spacing between pile $i$ and $j$. $r_{m}$ is the radial distance from the pile center to a point where the shear friction caused by pile can be ignored. Its value can be taken according to Lin and Dai [7].

The existence of pile $j$ will make itself generate reaction force with the same value with $\tau_{j i}$ but in opposite direction. The reaction force will transmit along the radial direction and be applied on the pile $i$, which will make pile $i$ produce the upward reduction. Substituting $\tau_{i 0}=\tau_{j i}$ into (14), so, the reduction of the skin friction on pile $i, \tau_{i 01}$, can be computed by the following equation:

$$
\tau_{i 01}=\frac{\tau_{i 0} r_{0}^{2}}{S_{i j}^{2}}
$$

Pile $i$ has no load while axial load $P_{j}$ is applied on pile $j$; the shear stress $\tau_{j 0}$ of pile $j$ is transmitted along the radial direction, so that pile $i$ generates a passive shear stress, namely, $\tau_{j i}^{\prime}$, which has a downward direction. The value of $\tau_{j i}^{\prime}$ can be presented by the following equation:

$$
\tau_{j i}^{\prime}=\frac{\tau_{j 0} r_{0}}{S_{i j}}
$$

Meanwhile, due to the reinforcing effect of the pile $j$ on the pile $i$, the upward reduction of the shear stress of the pile $i$ will emerge. Substituting $\tau_{i 0}=\left(\tau_{j i}^{\prime} r_{0}^{2} / S_{i j}^{2}\right)$ into (14), the value of reduction of the shear stress, $\tau_{j 01}$, can be expressed as

$$
\tau_{j 01}=\frac{\tau_{j 0} r_{0}^{3}}{S_{i j}^{3}}
$$




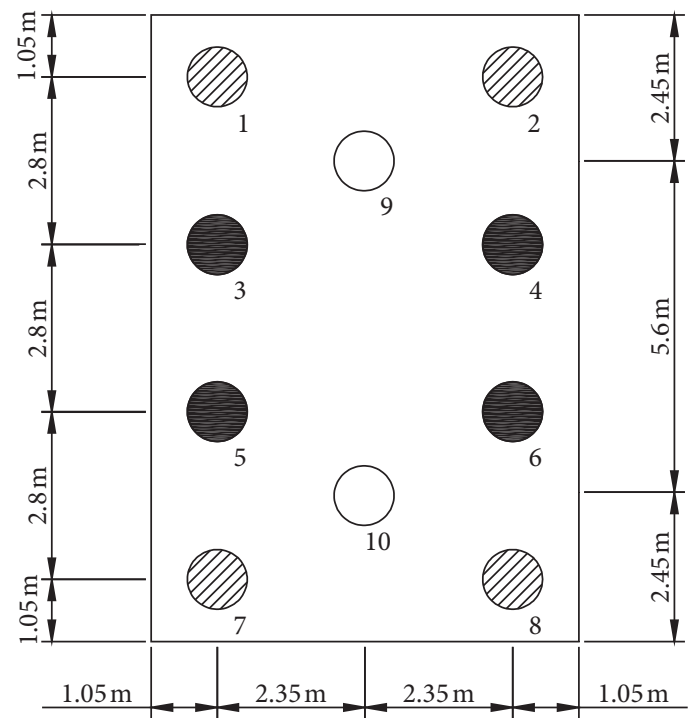

Figure 7: The schematic diagram of pile foundation.

Then, the effect of the existence of the pile and mutual reinforcing effect among the piles on the skin friction is fully taken into consideration. The skin friction of the foundation pile $i$ in the pile group can be expressed by the following equation:

$$
\tau_{i 0}^{\prime}=\tau_{i 0}-\frac{\tau_{i 0} r_{0}^{2}}{S_{i j}^{2}}+\frac{\tau_{j 0} r_{0}}{S_{i j}}-\frac{\tau_{j 0} r_{0}^{3}}{S_{i j}^{3}} .
$$

Assuming $\tau_{i 0}=\tau_{j 0}$ and generalizing (18) to the pile group, then,

$$
\tau_{i 0}^{\prime}=\tau_{i 0} \sum_{j=1, i \neq j}^{N_{e}}\left(1-\frac{r_{0}^{2}}{S_{i j}^{2}}+\frac{r_{0}}{S_{i j}}-\frac{r_{0}^{3}}{S_{i j}^{3}}\right),
$$

where $N_{e}$ represents the number of piles within the affected area.

Substituting (19) into (12), the total skin friction of the foundation pile in the pile group, $T$, can be obtained:

$$
T=\pi D \int_{0}^{Z} \tau_{i 0}^{\prime} \mathrm{d} z .
$$

Then, substituting (20) into (13), the settlement of foundation pile $i$ in pile group, $w_{i}$, can be written as

$$
w_{i}=\frac{1}{E A_{p}} \int_{0}^{z}\left[Q_{i}+Q_{w}-\pi D \int_{0}^{z} \tau_{i 0}^{\prime}(\varphi) \mathrm{d} z\right] \mathrm{d} z .
$$

When the top load $Q$ of pile group cap is known and the cap is rigid, the settlement of each foundation pile can be obtained by the following equation:

$$
\left.\begin{array}{ll}
\left.w_{i}\right|_{z=0}=\left.w_{j}\right|_{z=0} & (1 \leq i \leq n) \\
\sum Q_{i}=Q &
\end{array}\right\} .
$$

When the cap is flexible, the following equation (23) will be adopted to calculate the settlement of each foundation pile:

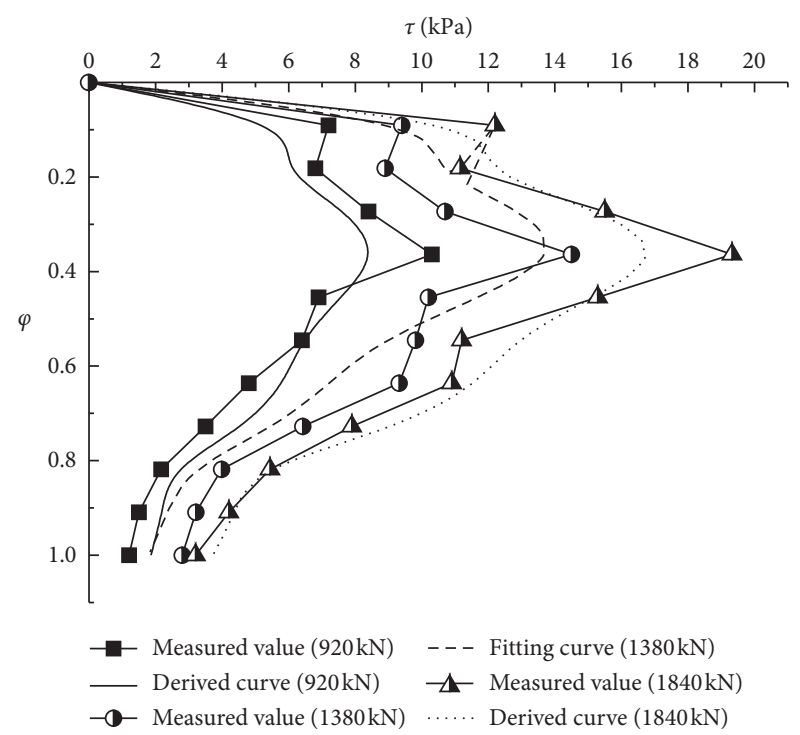

FIgURE 8: The comparisons of single pile skin friction.

$$
\left.\begin{array}{ll}
Q_{i}=Q_{j} & (1 \leq i \leq n) \\
z=0 &
\end{array}\right\}
$$

4.2. Case Study on Response of Pile Group. The first case was reported by Mao and Jiang [10]. Southwest Jiaotong University and Central South University carried out single pile static load tests and pile group tests on the 505\# pile foundation of the Yangcheng Lake section of the BeijingShanghai high-speed railway. The bearing platform has $6.8 \mathrm{~m}$ in width, $10.5 \mathrm{~m}$ in length, and $2 \mathrm{~m}$ in thickness. The pile foundation has 10 piles in total, while each pile has a diameter of $1 \mathrm{~m}$ and is driven to a penetration of $55.5 \mathrm{~m}$. The concrete strength of pile body is $\mathrm{C} 30$. The schematic diagram of pile location is shown in following Figure 7. Here, the piles 
TABLE 5: The comparison of calculated value and measured value.

\begin{tabular}{lcccc}
\hline Method & Load of corner pile $(\mathrm{kN})$ & Load of edge pile $(\mathrm{kN})$ & Load of center pile $(\mathrm{kN})$ & Settlement $(\mathrm{mm})$ \\
\hline Calculated value $[10]$ & 1894.04 & 1444.04 & 1314.04 & 3.4 \\
Calculated value & 1704.97 & 1581.33 & 1419.38 & 2.91 \\
Measured value & - & - & - & 3.1 \\
\hline
\end{tabular}

$1,2,7$, and 8 are defined as corner piles, the piles $3,4,5$, and 6 are defined as edge piles, and the remaining piles 9 and 10 are defined as center piles. Because the pile foundation in this case is a symmetrical structure, the forces and settlement of the pile at the same location are the same as well.

Firstly, the functional relationship between the skin friction and the parameter $\varphi$ of single pile is obtained by fitting when the top load is $1380 \mathrm{kN}$. The correlation coefficient $R^{2}$ between the fitting value and the measured value is 0.90 . Deriving the relationship between the skin friction and the parameter $\varphi$ under different loads and compared with the measured value, the results are shown in Figure 8 . When the top load of a single pile is $920 \mathrm{kN}$ and $1,840 \mathrm{kN}$, the correlation coefficients between the derived value and the measured value are 0.9682 and 0.9874 , respectively. It is not hard to draw a conclusion that the method in this paper can better predict the relationship between the skin friction and depth under different loads.

The vertical load of the pile foundation is $15,984 \mathrm{kN}$ in total. The effect of the bottom soil of the cap is neglected in the calculation. The elastic modulus of the pile is adopted as $30 \mathrm{GPa}$. Substituting the relevant parameters into the formula mentioned above, the calculated results are shown in Table 5.

It can be found out from Table 5 that the load distribution trend of the corner pile, edge pile, and center pile calculated in this paper is consistent with Mao and Jiang [10]. In this paper, the calculated settlement of pile foundation is $2.91 \mathrm{~mm}$, and the error with the measured settlement value is only $6 \%$. The calculation results have good accuracy.

\section{Conclusions}

This work investigates the distribution pattern of skin friction along depth of single pile in static load test by fitting the $\tau$ - $z$ curve of a single pile to obtain the functional expressions between the pile skin friction and the depth. Based on the one-dimensional similarity of $\tau$-z curves of single pile, the functional expressions between the skin friction and depth of single pile under other axial loads can be derived.

The effects of the self-weight and the end resistance ratio on axial force distribution of the super-long pile have been analyzed. The results indicate that the error of the axial force considering the self-weight and the end resistance ratio is far less than the calculated result without considering these. It is more in line with the actual distribution of axial force when taking the self-weight and end resistance ratio into account. Meanwhile, the calculated axial force has a good agreement with the experimental value. Comparing the test data with calculated settlement of the single pile by different methods, this shows that the error between the traditional method and test data is $18.52 \%$. The error will reach $2.26 \%$ without considering the end resistance ratio. When the end resistance ratio is considered, the error of settlement will reduce to $1.64 \%$. The accuracy of calculation method proposed in this work is further certificated.

Fully considering the effect of piles existing on the surrounding soil and the mutual reinforcing effect between the piles in the pile group, the calculation model of the foundation piles is derived. The error between the measured value and calculated value is only $6 \%$. It is not hard to find that the method in this paper has a good consistency by comparing the calculated results of this paper with those measured by Mao and Jiang. Also, it can better predict the deformation behavior of pile group under similar conditions.

\section{Data Availability}

The underlying data used to support the results of this study are included within the article.

\section{Conflicts of Interest}

All authors declare that there are no conflicts of interest in this paper.

\section{Acknowledgments}

This work was gratefully supported by the National Natural Science Foundation of China (no.11932010) and the General Program (no.11572186).

\section{References}

[1] J. L. Liu, W. S. Gao, and M. B. Qiu, Handbook for Technical Code for Building Pile Foundations, China Architecture and Building Press, Beijing, China, 2010.

[2] C. Y. Lee, "Discrete layer analysis of axially loaded piles and pile groups," Computers and Geotechnics, vol. 11, no. 4, pp. 295-313, 1991.

[3] M. F. Randolph and C. P. Wroth, "An analysis of the vertical deformation of pile groups," Géotechnique, vol. 29, no. 4, pp. 423-439, 1979.

[4] W. S. Gao, "Analytical solution for settlement of group piles in layered ground based on shear displacement method," Rock and Soil Mechanics, vol. 31, no. 4, pp. 1072-1077, 2010.

[5] Y. Zhang and Y. F. Hou, "A shearing displacement method for group piles considering pile/raft foundation soil mass interaction," Journal of Beijing Jiaotong University, vol. 32, no. 4, pp. 123-126, 2008.

[6] Z. Y. Lin and Z. H. Dai, "Interaction coefficients method for calculating piles group settlements considering reinforcing and restraining effect," Rock and Soil Mechanics, vol. 35, no. S1, pp. 221-226, 2014. 
[7] Z. Y. Lin and Z. H. Dai, "Settlement calculation of pile groups in layered soil with consideration of reinforcing and restraining effect," Journal of Engineering Geology, vol. 23, no. 1, pp. 178-185, 2015.

[8] Z. Y. Lin and Z. H. Dai, "Interaction factor method for piles group settlement by static load tests of single pile," Chinese Journal of Geotechnical Engineering, vol. 38, no. 1, pp. 155$162,2016$.

[9] X. L. Sun and M. Yang, "Approximative analysis for piled rafts by pile load tests," Chinese Journal of Geotechnical Engineering, vol. 28, no. 8, pp. 1013-1018, 2006.

[10] J. Q. Mao and Y. Jiang, "Settlement calculation of pile group foundation based on results of vertical static load test on single pile," Journal of the China Railway Society, vol. 39, no. 1, pp. 97-103, 2017.

[11] D.-D. Pan, Q.-Q. Zhang, S.-W. Liu, and S.-M. Zhang, "Analysis on response prediction of a single pile and pile groups based on the runge-kutta method," KSCE Journal of Civil Engineering, vol. 22, no. 1, pp. 92-100, 2017.

[12] F. Y. Liang, L.-Z. Chen, and J.-P. Li, "Analysis of piles reinforced effects on interaction coefficients of piles," Rock and Soil Mechanics, vol. 26, no. 11, pp. 1757-1760, 2005.

[13] G. L. Yan and H. F. Zhang, "Calculation of interaction coefficient between piles," Journal of North China University of Water Resources and Hydropower, vol. 32, no. 32, pp. 93-95, 2011.

[14] D.-D Xin, L. W. Zhang, and C. X. Su, "Settlement research of pile groups in layered soils bases on virtual soil-pile model," Rock and Soil Mechanics, vol. 38, no. 8, pp. 2368-2376+2394, 2017.

[15] B. B. Sheil and B. A. McCabe, "An analytical approach for the prediction of single pile and pile group behaviour in clay," Computers and Geotechnics, vol. 75, pp. 145-158, 2016.

[16] W. Chen, "Experimental study on the vertical bearing capacity of super-long bored pile in shanghai soft soil area," Chinese Journal of Underground Space and Engineering, vol. 7, no. 3, pp. 504-508, 2011.

[17] W. Yao, Y. Liu, and J. Chun, "Characteristics of negative skin friction for super-long piles under surcharge loading," International Journal of Geomechanics (ASCE), vol. 12, no. 2, pp. 90-97, 2012.

[18] Q. Zhang and Z. M. Zhang, "A simplified nonlinear approach for single pile settlement analysis," Canadian Geotechnical Journal, vol. 49, no. 11, pp. 1256-1266, 2012.

[19] G. F. Xin, Z. M. Zhang, T. D. Xia, and Z. L. Chen, "Experimental study on the bearing behaviors of overlength piles under heavy load," Chinese Journal of Rock Mechanics and Engineering, vol. 24, no. 13, pp. 2397-2402, 2005.

[20] Y. X. Ma, W. H. Xu, and Z. W. Xu, "Displacement reconstruction of slender beam based on polynomial fitting method," Journal of Vibration and Shock, vol. 39, no. 11, pp. 152-157+183, 2020.

[21] J. Y. Zhu, L. Z. Chen, and W. Ge, "Test data analysis for axially loaded piles in layered soil," Chinese Journal of Geotechnical Engineering, vol. 20, no. 3, pp. 34-39, 1998.

[22] B. A. McCabe, Experimental investigations of driven pile group behaviour in belfast soft clay, Ph.D. Thesis, Trinity College, Dublin, Ireland, 2002.

[23] S. J. Feng, H. Ke, Y. M. Chen et al., "Experimental study on super-long bored pile in loess," Chinese Journal of Geotechnical Engineering, vol. 26, no. 1, pp. 110-114, 2004

[24] C. Zhao, "Experimental research on load transfer of largediameter and super-long bored pile in Guangdong area," Chinese Journal of Rock Mechanics and Engineering, vol. 34, no. 4, pp. 849-855, 2015.
[25] Z. M. Zhang, "The endurance of super-long piles in soft soil," Chinese Journal of Geotechnical Engineering, vol. 23, no. 5, pp. 552-556, 2001.

[26] Z. Zhang, G. Xin, and T. Xia, "Test and research on unrocksocketed super-long pile in deep soft soil," China Civil Engineering Journal, vol. 37, no. 4, pp. 64-69, 2004.

[27] M. F. Randolph and C. P. Worth, "Analysis of deformation of vertically load piles," Journal of the Geotechnical Engineering Division, ASCE, vol. 104, no. GT12, pp. 1465-1488, 1978. 